\title{
Exploring the Relationship of Personality and Social Support Types among College Students
}

\author{
Yuewei Shi ${ }^{*} \quad \mathrm{Xi} \mathrm{Lin}{ }^{2}$ \\ 1.Department of Educational Foundations, Leadership, and Technology, Auburn University, AL, USA \\ 2.Department of Interdisciplinary Professions, East Carolina University, NC, USA \\ *E-mail of the correspondence author: yzs0062@auburn.edu
}

\begin{abstract}
This study investigated the relationship between Big Five personality traits and social support types among college students. Data was collected from 189 university students from a research institution in the US. Findings indicated that learners who have Agreeableness and Extraversion personality traits seek for more broadly social support resources in college study and life. Additionally, learners who have Neuroticism traits are negatively associated with all social support resources. It is expected that this study would assist college faculty and student affairs professionals to better understand the differences of personality traits among college students and craft feasible strategies so as to encourage these students to seek sufficient social support resources on their personal development.
\end{abstract}

Keywords: Big Five personality, college students, social support, higher education

DOI: $10.7176 / \mathrm{JEP} / 11-31-03$

Publication date: November $30^{\text {th }} 2020$

\section{Introduction}

Personality is a way to identify the perceptual, behavioral and cognitive differences for individuals (Ferguson, 2013). In response to the function of personality, personality tests were created in terms of the needs of assessment. Personality tests are widely applied into personnel selection (McFarland, 2003), disordered behaviors prediction (Hilakivi, Veilahti, Asplund, Sinivuo, Laitinen, \& Koskenvuo, 1989), assessing cognitive ability (Furnham, Forde \& Cotter, 1998), academic achievement (Chamorro-Premuzic, \& Furnham, 2003), and so on. In some sense, the personality test is one of the common ways to estimate human behaviors through individual traits, and seeking social support is one of the typical human social behaviors. As a part of human social behaviors, social support is a process inextricably woven into communication behaviors from the interactional view (Albrecht \& Adelman, 1987). Cobb (1976) defined social support as social network of resources that lead people to interact with others for care, love, and esteem. Therefore, the applications of social support and its relationship to personality, health, and adjustment have become one of the popular topics in psychology area (Sarason, Sarason, \& Pierce, 1990). Although there are numbers of ways that social support usually connects with other psychological aspects, personality plays a significant role which has been less explored by previous studies. As a result, this study explored the correlational ways of personality traits and social support types among college students through the following questions:

1. In what correlational ways do personality traits connect with social support types?

2. To what extent do college students perform differently on the correlation between each personality trait and social support types?

\section{Literature Review}

2.1 Big Five Personality

Personality is a complicated and ambiguous concept in development psychology. Most of the previous studies related to personality use enumerative and extensional ways to represent and explain individual traits (Hofstee, 1994). McDougall (1932) considered that "personality may to advantage to broadly analyzed into five distinguishable but separate factors, namely intellect, character, temperament, disposition, and temper..." (p. 15). Using this argument, later scholars developed the Big Five personality assessment to measure the personality traits of individuals.

Generally, components of the Big Five personality include Extraversion, Agreeableness, Conscientiousness, Openness to Experience, and Neuroticism, (O’Connor \& Paunonen, 2007). Extraversion displays individual differences on sociability, assertiveness and talkativeness. Agreeableness reflects individual differences on being helpful, cooperative, and sympathetic towards others. Additionally, Conscientiousness is exemplified as being diligent, reliable and dependable in personality characteristics. Openness performs a strong intellectual curiosity and tendency to explore novel experiences for life. Finally, Neuroticism refers to individuals who have a high degree of exposure to distress and anxiety. (Komarraju, Karau, Schmeck \& Avdic, 2011; Kwang \& Rodrigues, 2002).

According to previous studies that focusing on the validity and reliability of the Big Five personality traits 
assessment, Mount, Barrick and Strauss (1994) demonstrated that the distinct validity measurement may affect the validity level of the Big Five personality traits assessment, and the validity of the self-assessment of the Big Five personality traits may underestimate the whole structure of the assessment. Gosling, Rentfrow \& Swann (2003) also noted that a ten-item measure of the Big Five dimensions is suitable for self-assessment of personality traits. Cobb-Clark and Schurer (2012) later on stated that the Big Five personality traits are stable for assessing workingage adults. Based on previous studies, scholars often examined the validity of the Big Five personality traits from the assessment validity and the survey items' length. In conclusion, the Big Five personality, in some sense, is one effective measurement tool and can be applied to assess and generalize the main social and emotional personality characteristics of individuals.

\subsection{College students}

College students usually refer to the learner population that enrolled in higher education institutions. The main studying and living activities of these students usually occur on campus and their surrounding environments. Arnett (1994) used important criterions to describe college students including "accept responsibility for the consequences of your actions," "decide on beliefs and values independently of parents or other influences," and "establish a relationship with parents as an equal adult" (p. 302). To be simplified, college students are studying and living in the university independently and are positioned to become mature.

\subsection{Personality and College Students}

The personality traits of college learners are often associated with their academic performance, achievement, motivation, personal value and so on according to previous studies which examined the correlation between personality traits and test scores. For example, Noftle and Robins (2007) concentrated on exploring the relationship between personality traits and academic test scores before students going to college, and their results acknowledged that the personality traits have independent and incremental effects on GPA and SAT scores. Ridgell and Lounsbury's study (2004) explored the Big Five personality as a type of emotional stability, and the results of their study showed that the Big Five traits are related to the course grade of college students. O'Connor and Paunonen (2007) compared and analyzed different research results from previous literature about personality traits and students' success, and they found that the Big Five factors and facets have a strong connection with students' scholastic success.

In order to explore the relationship between the personality traits and students' learning motivation, Komarraju Karau and Schmeck (2009) researched on 308 undergraduate college students in order to examine the correlations among "Big Five" personality traits, GPA and academic motivations. Their study discovered that "conscientiousness are most likely to be motivated," "openness was positively related with intrinsic motivation," and "extroversion was positively related with extrinsic motivation" (p.50). For the relationship between personality traits and academic achievement expectation, Komarraju and colleagues (2009) study additionally revealed that students who are more conscientious, open, neurotic, or agreeable have a stronger desire to pursue a high GPA in their studies. In addition to academic performance and achievement, scholars also examined the relationship between the Big Five personality traits and personal values. For instance, Roccas and colleagues (2002) analyzed the relationship between personality factors and personal value among 246 students. However, they indicated that that the personality traits and personal values do not have a direct correlation. Meanwhile, the personal values on behaviors are more influenced by the cognitive control, rather than the personality traits.

\subsection{Social Support and College Students}

According to the theoretical statement by Tardy (1985), social support needs to be measured by direction, disposition, evaluation, content and networks scales. From a provocative and influential theoretical perspective, attachment behaviors are followed by some of the strongest emotional connections (Sarason, Levine, Basham, \& Sarason, 1983). Furthermore, the nature of social support is one the apparent interactive human behaviors, and the "attachment figures provide social support in the areas of expressive behavior and instrumental aid" (Sarason, et al., 1983). Meanwhile, Lin (1986) defined social support as "perceived or actual instrumental and/or expressive provisions supplied by the community, social network, and confiding partners (p. 18)."

From a generalized perspective, social support should include expressive support and instrumental aids. However, some of the conceptual definitions of social support simplified it as a kind of behavior of an individual seeking emotional support. For example, Barrera, Sandler, and Ramsay (1981) considered social support as people who will provide help in times when other people are in crisis and emotional distress, and the natural aids usually include family members and friends. Similarly, Cobb (1976) described social support as "information that leading the subject to believe that he is cared for and loved, esteemed, and a member of a network of mutual obligations" (p. 300). Additionally, Sherbourne \& Stewart (1991) noted the function of social support as the availability of someone to provide emotional support that would protect people from negative situations.

From the emotional or expressive behavioral perspective of the definitions of social support, the 
Multidimensional Scale of Perceived Social Support (MSPSS) was developed and applied to test the support content and networks of individuals (Tardy, 1985; Sarason, Levine, Basham, \& Sarason, 1983). MAPSS was designed for three specific social support resources: 1) friends, 2) family, and 3) significant other (Zimet, Dahlem, Zimet, \& Farley, 1988). Zimet and colleagues (1988) reviewed the reliability and validity of MSPSS, and they concluded that the MSPPS is a psychometrically sound survey instrument to examine the different resources of social support.

Some previous studies have examined a variety of correlational relationships among social support, physical health, psychological stress, culture, life quality, and so on. For example, according to Kaplan, Cassel \& Gore's (1977) study, social support is associated with physical health. They also noted that social support plays an important role on protecting physical health for humans. Additionally, Mallinckrodt and Wei (2005) investigated the relationship among social support, attachment, and psychological stress, and they found that social support is positively correlated with mental health. Kim, Sherman \& Taylor (2008) further discussed cultural differences on seeking social support between Asian Americans and European Americans. Findings of their study presented that Asian Americans are more reluctant to seek social support from people with close relationships compared to European Americans. Other scholars also explored the relationship between social support and life quality. For instance, Helgeson (2003) noted that informational or emotional support resources could help reduce individuals' stressors. Specifically, Dehle, Larsen, and Landers (2001) found that adequate support accounts for significant unique variance in marital quality.

Social support would influence on college students' mental health. Coffman and Gilligan (2002) noted that the students who have a high level of social support perception tend to own a high level of life satisfaction. Similarly, Wang and Castañeda - Sound (2008) indicated that the perceived of social support is a significant factor for psychological well-being among college students. The relationship between social support and mental problems among college students has also been investigated. For example, Hefner and Eisenberg (2009) explored the relationship between the quality of social support and mental disorder issues among college students. their study showed that a higher perceived quality of social support is strongly associated with a lower likelihood of depression, anxiety, self- injury, suicidality, and symptoms of eating disorders. Additionally, scholars stated that positive social support resources especially from friends and family would reduce the chance of burnout among college students (Jacobs \& Dodd, 2003). Furthermore, the relationship between social support and college students' academic performance has been examined. However, social support is not associated with course GPA (Nicpon, Huser, Blanks, Sollenberger, Befort, \& Kurpius, 2006). Yet, if students perceive more cares and support from family and friends, their academic stress would be reduced (Rayle \& Chung, 2007).

Although studies have explored the relationship among the social support with other factors especially in mental health, academic grade, and life quality, limited study (e.g., Wickert, Hittner, Harris, \& Herring, 2002) has discussed the relationship between different personality traits and social support solely among college students. Therefore, the purpose of this research is to explore the relationship between personality traits and social support types among this learner group.

\section{Method}

3.1 Participants

A total number of 189 college students who were 19 years old or above from one southeastern high education institution participated in this research. Among these participants, 105 (55.56\%) were male students, and 84 (44.44\%) were female students. Most of the participants identified themselves as White or Caucasian (68.25\%), followed by Asian or Pacific Islander (12.7\%), Hispanic or Latino (7.94\%), African American (6.88\%), and others $(4.23 \%)$

\subsection{Instrument}

Big Five Personality instrument (John \& Srivastava, 1999) was used in this study. This 44-item 5-point Likert scale $(1=$ disagree strongly to 5 = agree strongly $)$ inventory aims to measure individuals' extraversion, agreeableness, conscientiousness, neuroticism, and openness.

Extraversion is characterized by excitability, sociability, talkativeness, assertiveness, and high amounts of emotional expressiveness (Liu, et al., 2016). Individuals who have a high level of extraversion are outgoing and tend to gain energy in social situations. Extraversion includes 8 items (e.g., I see myself as someone who is talkative; I see myself as someone who generates a lot of enthusiasm), and scores were averaged $(\alpha=.91)$. Agreeableness includes attributes such as trust, altruism, kindness, affection, and prosocial behaviors (Liu et al., 2016). Individuals who have a high level of agreeableness are more cooperative while those who have a low level of this personality are more competitive and sometimes manipulative. Agreeableness consists of 9 items (e.g., I see myself as someone who is helpful and unselfish with others; I see myself as someone who has a forgiving nature) and were scored an average of $\alpha=.79$. Conscientiousness refers to high levels of thoughtfulness, good impulse control, and goal-directed behaviors (Liu et al., 2016). Individuals with a high level of conscientiousness 
are organized and mindful of details. They usually plan ahead and consider how their behavior would influence others. This attribute includes 9 items (e.g., I see myself as someone who does a thorough job; I see myself as someone who perseveres until the task is finished) and were scored average of $\alpha=.84$. Neuroticism is characterized by sadness, moodiness, and emotional instability (Liu et al., 2016). Individuals who have a higher level of this trait tend to experience mood swings, anxiety, irritability, and sadness, while those who have a lower level of neuroticism are more stable and emotionally resilient. This personality consists of 8 items (e.g., I see myself as someone who is depressed, blue; I see myself as someone who worries a lot) and were scored an average of $\alpha$ $=.84$. Finally, individuals who have a high level of openness tend to have a broad range of interests. Additionally, they are curious about the world and others, and they are eager to learn new things and enjoy new experiences (Liu et al., 2016). Openness includes 10 items (e.g., I see myself as someone who is curious about many different things; I see myself as someone who has an active imagination) and were scored an average of $\alpha=.84$.

Multidimensional Scale of Perceived Social Support (MSPSS) (Zimet, Dahlem, Zimet, \& Farley, 1988) was used to examine individuals' social support. This inventory consists of a 12 - item 7-point Likert scale $(1=v e r y$ strongly disagree to 7 = very strongly agree), which aims to assess perceived support from each of three sources: family, friends, and a significant other. Each dimension consists of 4 items (e.g., my family really tries to help me; I can count on my friends when things go wrong; I have a special person who is a real source of comfort to me), and the Cronbach's alpha is $0.94,0.94$, and 0.96 for family, friends, and a significant other respectively.

\subsection{Data Analysis}

Canonical correlation analysis was conducted to examine the relationship between the Big Five Personality traits and the Social Support types of participants. A series of multiple regressions using stepwise procedure was then conducted to investigate the relationship between the predictors (Big Five Personality traits) and the criterion variables (types of social support) in order to find the best prediction model for each criterion variable. Data was analyzed through SPSS 27. The $p$ value of Box's M was set as 0.001 (Mertler, \& Vannatta, 2002), and the alpha level was set at $\mathrm{p}$ equals 0.05 .

\section{Results}

4.1 RQ1: In what correlational ways do personality traits connect with social support types?

Canonical correlation results show that the relationship of Big Five Personality traits and social support types are significantly associated by canonical correlation (Wilks Lambda $=0.51, \mathrm{~F}=4.72, \mathrm{p}<.001$ ). Using a cutoff structure coefficient of 0.30 , all variables in the Big Five set were correlated with the Big Five variate (see Table 1). In the social support types set, all three variables were correlated with this variate. Specifically, Agreeableness has the highest useful rate (72\%) in explaining variance in the Big Five set, followed by Extraversion (42\%), Neuroticism (36\%), Conscientiousness (28\%), and Openness (14\%). Friends were $85 \%$ useful in explaining variance in types of social support set, followed by a significant other (45\%) and family (44\%). The pair of canonical variates that comprise the canonical function indicates that individuals who have a higher level of Extraversion, Agreeableness, Conscientiousness and Openness receive more support from a significant other, family, and friends. However, those who have a higher level of Neuroticism obtain less support from a significant other, family, and friends.

Table 1. Canonical Correlation between Big Five and MSPSS

\begin{tabular}{lccc}
\hline Variable & \multicolumn{2}{c}{ Canonical Function } \\
\cline { 2 - 4 } Big Five & Coefficient & $\mathrm{r}_{\mathrm{s}}$ & $\mathrm{r}_{\mathrm{s}}{ }^{2}$ \\
Extraversion & & 0.4 & 0.42 \\
Agreeableness & 0.68 & 0.65 & 0.72 \\
Conscientiousness & 0.05 & 0.53 & 0.28 \\
Neuroticism & -0.12 & -0.6 & 0.36 \\
Openness & 0.15 & 0.38 \\
Adequacy & 0.39 & \\
Redundancy & 0.15 & \\
MSPSS & & & 0.45 \\
A significant other & 0.19 & 0.67 \\
Family & 0.34 & 0.66 \\
Friends & 0.8 & 0.92 \\
Adequacy & -0.94 & 0.85 \\
Redundancy & 0.10 & \\
\hline N & & & \\
\hline
\end{tabular}

$\mathrm{N}=188 . \mathrm{r}_{\mathrm{s}}=$ structure coefficient; $\mathrm{r}_{\mathrm{s}}^{2}=$ squared structure coefficient 
4.2 RQ2: To what extent do college students perform differently on the correlation between each personality trait and social support types?

A series of multiple regressions using stepwise procedure was then conducted to investigate the predictable relationship between the Big Five Personality traits and the Social Support types (see Table 2). Results indicate that the level of Extraversion and Agreeableness can predict the family support type $\left(F_{(2,185)}=12.21, p<.01\right)$. The linear combination of the level of Extraversion and Agreeableness can be accounted by $12 \%$ of variance of the family support type $\left(R^{2}=.12\right)$. For every unit the level of Extraversion increases, the intention of seeking the family for support increases by 0.31 unit, whereas the level Agreeableness remains the same $(\beta=0.31, t=2.37, p$ $=.019)$. For every unit the level of Agreeableness increases, the intention of seeking family for support increases by 0.71 unit when the Extraversion stays the same $(\beta=0.71, t=3.79, p<.001)$. Both of these two personality traits have a positive relationship with the intention of seeking family for support. In other words, learners with a higher level of either Agreeableness or Extraversion would more likely to seek family support. In terms of other social support types, results note that the level of Extraversion and Agreeableness can also predict the friends support type $\left(F_{(2,185)}=23.78, p<.01\right)$. The linear combination of the level of Extraversion and Agreeableness can be accounted by $20.4 \%$ of variance of family support type $\left(R^{2}=.204\right)$. For every unit the level of Extraversion increases, the intention of seeking of friends for support increases by 0.34 unit, whereas the level Agreeableness remains the same $(\beta=0.34, t=3.23, p=.001)$. For every unit the level of Agreeableness increases, the intention of seeking friends for support increases by 0.83 unit when the Extraversion stays the same $(\beta=0.83, t=5.33, p$ $<.001)$. These two personality traits have a positive relationship with the intention of seeking support from friends. In other words, learners with a higher level of either agreeableness or extraversion are more likely to seek help from friends.

Finally, regression results show that the level of Extraversion and Agreeableness can predict the significant other support type $\left(F_{(2,185)}=14.24, p<.01\right)$. The linear combination of the level of these two personality traits can be accounted by $13.3 \%$ of variance of this support type $\left(R^{2}=.133\right)$. For every unit the level of Extraversion increases, the intention of seeking support from a significant other increases by 0.45 unit, whereas the other personality traits remains the same $(\beta=0.45, t=3.44, p=.001)$. For every unit the level of Agreeableness increases, the intention of seeking support from a significant other increases by 0.64 unit while the Extraversion keeps the same $(\beta=0.64, t=3.32, p=.001)$. These personality traits have a positive relationship with the intention of seeking support from a significant other. That is, learners with a higher level of either Agreeableness or Extraversion are more likely to seek support from a significant other.

Table 2. Multiple Regression Results

\begin{tabular}{|c|c|c|c|c|c|c|c|c|}
\hline DV & $R^{2}$ & $F$ & $d f$ & $p$ & Predictors & b & $t$ & $p$ \\
\hline \multirow{2}{*}{ Family support } & \multirow{2}{*}{0.12} & \multirow{2}{*}{12.21} & \multirow{2}{*}{2,187} & \multirow{2}{*}{$<.001$} & Extraversion & 0.31 & 2.37 & 0.019 \\
\hline & & & & & Agreeableness & 0.71 & 3.79 & $<.001$ \\
\hline \multirow{2}{*}{ Social support } & \multirow{2}{*}{0.2} & \multirow{2}{*}{23.78} & \multirow{2}{*}{2,187} & \multirow{2}{*}{$<.001$} & Extraversion & 0.34 & 3.23 & 0.001 \\
\hline & & & & & Agreeableness & 0.83 & 5.33 & $<.001$ \\
\hline \multirow{2}{*}{ Significant other } & \multirow{2}{*}{0.13} & \multirow{2}{*}{14.34} & \multirow{2}{*}{2,187} & \multirow{2}{*}{$<.001$} & Extraversion & 0.45 & 3.44 & 0.001 \\
\hline & & & & & Agreeableness & 0.64 & 3.32 & 0.001 \\
\hline
\end{tabular}

\section{Discussions}

According to the results, college students who have Extraversion, Agreeableness, Conscientiousness and Openness personality types are usually willing to seek social supports compared to student who have Neuroticism personality type. This finding indicates that college students are willing to seek social support because they have strong pervasive, social, self-control, and cooperative personality traits. These students often own one of the social support resources when they need spiritual or emotional supports. Additionally, students who were talkative, easygoing and had emotional self-control in their daily life intended to seek social support. On the contrary, students who had the lack of positive psychological adjustment and emotional stability may have had less desire to seek social supports when they needed help.

The current study also reveals that family is an important social support resource for the college students who have Agreeableness and Extraversion personality types. Previous studies indicated that family support is significantly beneficial for social activities and quality of life (Mant, Carter, Wade \& Winner, 2000). Thus, it is estimated that the pervasive, talkative and social personality traits are shaped by the emotional supports from family.

In addition to the support from blood relationships, college students who have strong personality traits on Agreeableness or Extraversion personality types also tend to seek support from friends. Reinhardt (1996) defined the role of friend by its voluntary nature, affective base, and mutual choice, and its ability to be lifelong. In the 
other words, friendship is another important social relationship for individuals in addition to the family support. Findings of the study show that college students who have strong personality traits of Agreeableness and Extraversion personality types often have more than one social support resource.

Furthermore, Sarason Levine, Basham \& Sarason (1983) noted that significant others are another social support resource for individuals. Significant others can include different roles including mentor, pastor, teacher, psychological counselor, and so on (Sarason, Sarason, \& Pierce, 1990). Findings of the present study reveal that college students who have Agreeableness or Extraversion personality types also consider significant others as one of their social support resources.

In summation, college students who have Extraversion, Agreeableness, Conscientiousness and Openness personality types are open to accepting different social support resources. Findings also present that students who had strong personality traits of Agreeableness and Extraversion personality types would have a strong desire to build up their own systematic social support networks. Therefore, it is assumed that the personality types have a strong relationship with social support resources options.

\section{Conclusions}

College students are usually aged between 18-22 years old, they attend class full-time, and live surrounded by a college campus (Jameson \& Fusco, 2014). In other words, these students have an independent living status, but are not mature intellectually and emotionally. As a result, college faculty and student affairs professionals should consider using various strategies to assist college students for the purpose of seeking suitable social support resources during their studying and living in the university. According to the findings of this study, the significant others can play a supportive role when these young adults need assistance for their study and life. Thus, instructors and student affairs professionals could play an important role as mentors so as to establish the social relationship with these students, in addition to seeking support from family and friends. The mentorship relationship between the faculty members and students will help them build their self-confidence in academics, social life, and future careers. For college mental counselors, they may suggest that students find their own comfortable social support resources according to their different personality types. Additionally, students who have Neuroticism personality traits may need extra attention and help from faculty and student affairs professionals. Based on the findings, college students who own this personality type may not be sensitive for any social support resources. Therefore, more work needs to be done in order to assist them to acquire enough social self-confidence and to trigger their social desire.

Several limitations exist in the study. First, the current study relied on a self-reported survey, so that the participants may have under- or overrate themselves when they answered the questionnaire. Therefore, survey fraud may be present. As a result, future study should include a qualitative approach to further examine the results of the current study. Second, the information of this study was collected from one southeastern higher education institution, which cannot represent all college students in the US. As a result, more students should be recruited from different universities in future study. In addition, more factors such as gender, major and ethnic groups should be included for analysis in future studies as well.

In conclusion, this study examined the relationship between the Big Five personality traits and social support types among college students. Findings indicate that learners who have Agreeableness and Extraversion personality traits receive more social support resources, while students who have Neuroticism traits are negatively associated with all social support resources. It is expected that this study may shed light on higher education professionals regarding the differences of personality traits among college students, thus, to provide efficient strategies to encourage these students to seek sufficient social support resources on their personal development.

\section{References}

Albrecht, T. L., \& Adelman, M. B. (1987). Communicating social support. Sage Publications, Inc.

Arnett, J. J. (1994). Are college students adults? Their conceptions of the transition to adulthood. Journal of adult development, 1(4), 213-224.

Chamorro-Premuzic, T., \& Furnham, A. (2003). Personality predicts academic performance: Evidence from two longitudinal university samples. Journal of research in personality, 37(4), 319-338.

Cobb, S. (1976). Social support as a moderator of life stress. Psychosomatic medicine.

Coffman, D. L., \& Gilligan, T. D. (2002). Social support, stress, and self-efficacy: Effects on students' satisfaction. Journal of College Student Retention: Research, Theory \& Practice, 4(1), 53-66.

Dehle, C., Larsen, D., \& Landers, J. E. (2001). Social support in marriage. American Journal of Family Therapy, 29(4), 307-324.

Donaldson, J. F., \& Graham, S. (1999). A model of college outcomes for adults. Adult Education Quarterly, 50(1), 24-40.

Ferguson, E. (2013). Personality is of central concern to understand health: towards a theoretical model for health psychology. Health Psychology Review, 7(sup1), S32-S70. 
Furnham, A., Forde, L., \& Cotter, T. (1998). Personality and intelligence. Personality and Individual Differences, 24(2), 187-192.

Helgeson, V. S. (2003). Social support and quality of life. Quality of life research, 12(1), 25-31.

Hefner, J., \& Eisenberg, D. (2009). Social support and mental health among college students. American Journal of Orthopsychiatry, 79(4), 491-499.

Hilakivi, I., Veilahti, J., Asplund, P., Sinivuo, J., Laitinen, L., \& Koskenvuo, K. (1989). A sixteen-factor personality test for predicting automobile driving accidents of young drivers. Accident Analysis \& Prevention, 21(5), 413-418.

Hofstee, W. K. (1994). Who should own the definition of personality?. European Journal of Personality, 8(3), 149162.

Jameson, M. M., \& Fusco, B. R. (2014). Math anxiety, math self-concept, and math self-efficacy in adult learners compared to traditional undergraduate students. Adult Education Quarterly, 64(4), 306-322.

John, O. P., \& Srivastava, S. (1999). The Big-Five trait taxonomy: History, measurement, and theoretical perspectives. In L. A. Pervin \& O. P. John (Eds.), Handbook of personality: Theory and research (Vol. 2, pp. 102-138). New York: Guilford Press.

Jacobs, S. R., \& Dodd, D. (2003). Student burnout as a function of personality, social support, and workload. Journal of college student development, 44(3), 291-303.

Kaplan, B. H., Cassel, J. C., \& Gore, S. (1977). Social support and health. Medical care, 15(5), 47-58.

Kim, H. S., Sherman, D. K., \& Taylor, S. E. (2008). Culture and social support. American psychologist, 63(6), 518.

Komarraju, M., Karau, S. J., Schmeck, R. R., \& Avdic, A. (2011). The Big Five personality traits, learning styles, and academic achievement. Personality and individual differences, 51(4), 472-477.

Kwang, N. A., \& Rodrigues, D. (2002). A Big - Five Personality profile of the adaptor and innovator. The Journal of Creative Behavior, 36(4), 254-268. 51(4), 472-477.

Liu, L., Preotiuc-Pietro, D., Samani, Z. R., Moghaddam, M. E., \& Ungar, L. (2016, March). Analyzing personality through social media profile picture choice. In Tenth international AAAI conference on web and social media.

Mallinckrodt, B., \& Wei, M. (2005). Attachment, social competencies, social support, and psychological distress. Journal of Counseling Psychology, 52(3), 358.

Mant, J., Carter, J., Wade, D. T., \& Winner, S. (2000). Family support for stroke: a randomised controlled trial. The Lancet, 356(9232), 808-813.

McFarland, L. A. (2003). Warning against faking on a personality test: Effects on applicant reactions and personality test scores. International Journal of Selection and Assessment, 11(4), 265-276.

Mertler, C. A., \& Vannatta, R. A. (2002). Advanced and multivariate statistical methods. Los Angeles, CA: Oyrczak.

Nicpon, M. F., Huser, L., Blanks, E. H., Sollenberger, S., Befort, C., \& Kurpius, S. E. R. (2006). The relationship of loneliness and social support with college freshmen's academic performance and persistence. Journal of College Student Retention: Research, Theory \& Practice, 8(3), 345-358.

Reinhardt, J. P. (1996). The importance of friendship and family support in adaptation to chronic vision impairment. The Journals of Gerontology Series B: Psychological Sciences and Social Sciences, 51(5), P268-P278.

Rayle, A. D., \& Chung, K. Y. (2007). Revisiting first-year college students' mattering: Social support, academic stress, and the mattering experience. Journal of College Student Retention: Research, Theory \& Practice, 9(1), 21-37.

Sarason, B. R., Sarason, I. G., \& Pierce, G. R. (1990). Social support: An interactional view. John Wiley \& Sons.

Sarason, I. G., Levine, H. M., Basham, R. B., \& Sarason, B. R. (1983). Assessing social support: The social support questionnaire. Journal of personality and social psychology, 44(1), 127.

Sherbourne, C. D., \& Stewart, A. L. (1991). The MOS social support survey. Social science \& medicine, 32(6), 705-714.

Swickert, R. J., Hittner, J. B., Harris, J. L., \& Herring, J. A. (2002). Relationships among Internet use, personality, and social support. Computers in human behavior, 18(4), 437-451.

Tardy, C. H. (1985). Social support measurement. American journal of community psychology, 13(2), 187-202.

Wang, C. C. D., \& Castañeda - Sound, C. (2008). The role of generational status, self - esteem, academic self efficacy, and perceived social support in college students' psychological well - being. Journal of college counseling, 11(2), 101-118.

Zimet, GD., Dahlem, NW., Zimet, SG., Farley, GK. (1988). The multidimensional scale of perceived social support. J Pers Assess. 52: 30-41. 